\title{
Study on Mechanism Experiments and Evaluation Methods for Water Eutrophication
}

\author{
Jiabin Yu, ${ }^{1}$ Zhaoyang Wang, ${ }^{2}$ Xiaoyi Wang, ${ }^{1}$ Jiping Xu, ${ }^{1}$ and Jie Jia ${ }^{1}$ \\ ${ }^{1}$ School of Computer and Information Engineering, Beijing Technology and Business University, Fucheng St., Haidian District, \\ Beijing 100048, China \\ ${ }^{2}$ School of Automation, Beijing Institute of Technology, Zhongguancunnan St., Haidian District, Beijing 100081, China
}

Correspondence should be addressed to Jiabin Yu; jiabinyu_33@qq.com

Received 14 November 2016; Revised 21 February 2017; Accepted 9 March 2017; Published 30 March 2017

Academic Editor: Pedro Ávila-Pérez

Copyright (C) 2017 Jiabin Yu et al. This is an open access article distributed under the Creative Commons Attribution License, which permits unrestricted use, distribution, and reproduction in any medium, provided the original work is properly cited.

\begin{abstract}
The process of water eutrophication involves the interaction of external factors, nutrients, microorganisms, and other factors. It is complex and has not yet been effectively studied. To examine the formation process of water eutrophication, a set of orthogonal experiments with three factors and four levels is designed to analyze the key factors. At the same time, with the help of a large amount of monitoring data, the principal component analysis method is used to extract the main components of water eutrophication and determine the effective evaluation indicators of eutrophication. Finally, the Bayesian theory of uncertainty is applied to the evaluation of the eutrophication process to evaluate the sample data. The simulation results demonstrate the validity of the research method.
\end{abstract}

\section{Introduction}

Currently, approximately $40 \%$ of lakes and reservoirs worldwide are affected by different degrees of eutrophication. Eutrophic lakes and reservoirs in China account, respectively, for $69.8 \%$ and $41.95 \%$ of the total [1-3]. Water eutrophication has become a major global environmental problem. Cyanobacteria bloom is a common ecological disaster in eutrophic lakes and reservoirs in most of the world $[4,5]$, and China is among the countries where the problem is the most serious and widely distributed $[6,7]$. Therefore, it is of great significance to conduct effective research and scientific evaluation of water quality to prevent water pollution and ensure the safety of human water supplies $[8,9]$.

Water eutrophication is when large amounts of elements such as nitrogen, phosphorus, and potassium flow into the surface water with a slow flow rate and long renewal period, causing the growth of algae and other aquatic organisms so that the rate of organic production is far greater than the consumption rate, ultimately leading to the accumulation of organic matter in water and destruction of the aquatic ecological balance $[10,11]$. At present, the traditional mathematical modeling methods to study the ecological process of lake eutrophication mainly involve the nutrient load model $[12,13]$, phytoplankton ecological model $[14,15]$, and ecological dynamic model $[16,17]$. Vollenweider proposed the total phosphorus balance model to examine the influence of certain nutrient concentration changes on eutrophication ecological processes $[18,19]$. Jørgensen et al. proposed an ecological model with carbon, nitrogen, and phosphorus as nutrients and floating plants as the central variable of the ecological model $[20,21]$. Narasimhan et al. simulated the relationship of a watershed nonpoint source nutrient load and the characteristics of chlorophyll a concentration by building a valley eutrophication model of the Cedar river reservoir [22]. The four-stage theory of cyanobacteria bloom formation was also proposed by Kong et al. [23]. However, the formation mechanism of water eutrophication involves many parameters, some of which show high levels of nonlinearity and uncertainty, so the above models have difficulty describing the complex relationship of water nutrients, water parameters, and microbial factors, which is unfavorable for thorough analysis of the water quality status and it makes it difficult to assess the level of water eutrophication.

As the process of water eutrophication has greater uncertainty and complex interactions of each factor, we design an 
orthogonal experiment to analyze the key factors in water eutrophication and use the principal component analysis method to extract the principal components affecting water quality status, finally obtaining water eutrophication evaluation indexes. Then, the Bayesian method is used to evaluate the water quality situation of major lakes in our country, concluding that the water quality evaluation results of the mechanism analysis have high accuracy.

\section{Experiment}

During the formation process of water eutrophication, the water temperature (WT), illumination, total nitrogen, and total phosphorus have the greatest impacts on algae growth and reproduction. Accordingly, an experiment is designed to analyze these four factors, using an orthogonal approach to examine the degree of influence in the overall process of algae growth and reproduction and find the key factors that determine the input variables for evaluating water eutrophication.

2.1. Collection and Preparation of Water Samples. Experimental water samples were taken from Yuyuantan for the determination of total nitrogen and total phosphorus. After pretreatment and placing the water in a light incubator $20^{\circ} \mathrm{C}$, at a light intensity of $6000 \mathrm{~lx}$ and a light dark ratio of $12 \mathrm{~h}: 12 \mathrm{~h}$, the nitrogen was $1.445 \mathrm{mg} / \mathrm{L}$ and the phosphorus was $0.2 \mathrm{mg} / \mathrm{L}$. Algae growth status and the cell density of algae were observed daily by microscope, and, when the algae cell density reached $10^{6} \mathrm{cell} / \mathrm{L}$, it could be used as the experimental algae (each group taken from the water samples).

2.2. Measurement of Chl_a. The experiment uses the M11 culture medium as a basis for media with a series of concentration gradients of nitrogen and phosphorus [24]. Calculating based on the algal cells' initial density of $10^{5}$ cell/L, take a certain volume of algae species liquid to preculture in a $3500 \mathrm{r} / \mathrm{min}$ centrifuge for 5 minutes and then remove the supernatant and apply sterile water several times to remove the surface-adsorbed nitrogen and phosphorus. Then, centrifuge again, remove the supernatant, and repeat three times. Next, transfer the treated algae into the prepared culture medium and place in the light incubator. The orthogonal experiment conditions of each group are controlled according to Table 2, the light dark ratio is $12 \mathrm{~h}: 12 \mathrm{~h}$, and the sterile water is supplied quantitatively twice daily [25]. The concentration of chlorophyll a is measured 2 times per day at $9 \mathrm{pm}$ and $3 \mathrm{pm}$. In the experiment, the chlorophyll a concentration is measured using a YSI 6600 multifunction water quality on-line measuring instrument [26].

2.3. Design of Orthogonal Experiment. After preculture and preservation of the algae species, each factor level is chosen according to the numerical water quality of the urban rivers and lakes of the Beijing water system in recent years, and we select and design a set of $\mathrm{L}_{9}\left(3^{4}\right)$ experiments including four factors and three levels, as shown in Table 1.

Based on the nine experimental plans in the orthogonal factor level table $\mathrm{L}_{9}\left(3^{4}\right)$, the experiment results are shown in Table 2.
TABLE 1: Factor level table for orthogonal experiment.

\begin{tabular}{lcccc}
\hline Number & $\begin{array}{c}\text { Light intensity } \\
(\mathrm{lx})\end{array}$ & $\begin{array}{c}\text { Water temperature } \\
\left({ }^{\circ} \mathrm{C}\right)\end{array}$ & $\begin{array}{c}\mathrm{TN} \\
(\mathrm{mg} / \mathrm{L})\end{array}$ & $\begin{array}{c}\mathrm{TP} \\
(\mathrm{mg} / \mathrm{L})\end{array}$ \\
\hline 1 & 6000 & 20 & 0.5 & 0.05 \\
2 & 12000 & 28 & 2 & 0.1 \\
3 & 18000 & 35 & 4 & 0.2 \\
\hline
\end{tabular}

TABLE 2: Orthogonal experiment condition table for each group.

\begin{tabular}{lcccc}
\hline Number & $\begin{array}{c}\text { Light intensity } \\
(\mathrm{lx})\end{array}$ & $\begin{array}{c}\text { Water temperature } \\
\left({ }^{\circ} \mathrm{C}\right)\end{array}$ & $\begin{array}{c}\mathrm{TN} \\
(\mathrm{mg} / \mathrm{L})\end{array}$ & $\begin{array}{c}\mathrm{TP} \\
(\mathrm{mg} / \mathrm{L})\end{array}$ \\
\hline 1 & 6000 & 20 & 0.5 & 0.05 \\
2 & 6000 & 28 & 2 & 0.2 \\
3 & 6000 & 35 & 4 & 0.1 \\
4 & 12000 & 20 & 2 & 0.1 \\
5 & 12000 & 28 & 4 & 0.05 \\
6 & 12000 & 35 & 0.5 & 0.2 \\
7 & 18000 & 20 & 4 & 0.2 \\
8 & 18000 & 28 & 0.5 & 0.1 \\
9 & 18000 & 35 & 2 & 0.05 \\
\hline
\end{tabular}

\section{Results and Discussion}

3.1. Experimental Analysis. The maximum biomass of algae (with chlorophyll a, unit $\mathrm{g} / \mathrm{L}$ ) and the maximum growth rate of algae $(g /(L \cdot d))$ in the experimental results of the orthogonal experiment are shown in Table 3.

3.1.1. Analysis of the Maximum Algae Standing Crop (in the Form of Chlorophyll). Based on analysis of the orthogonal experimental data shown in Table 4, we can see that the range size of the four factors, in turn, is in the order water temperature $>$ light $>$ total phosphorus $>$ total nitrogen, and the influence of algae growth and reproduction is in the order water temperature $>$ light $>$ total phosphorus $>$ total nitrogen. The orthogonal experimental analysis is described as Figure 1, and it can be seen that the influence of the four factors on algae growth and reproduction remains consistent, and the growth of algae increases with the increase of each factor until a certain value when the algae growth begins to decline instead, which causes the maximum turmoil.

3.1.2. Analysis of the Maximum Daily Growth Rate of Algae (in the Form of Chlorophyll). The range analysis of the maximum daily growth rate of algae is shown in Table 5 . We can see that the size order of the four factors is consistent with the maximum standing crop of algae, and the degree of influence on the algae growth and reproduction size is temperature $>$ light $>$ total phosphorus $>$ total nitrogen. The intuitive analysis results of the orthogonal experiment are represented in Figure 2, which shows that the degrees of influence of the four factors on algae growth and reproduction are inconsistent with the largest stock on hand, but the influence of temperature is consistent; that is, an optimal growth temperature exists. 


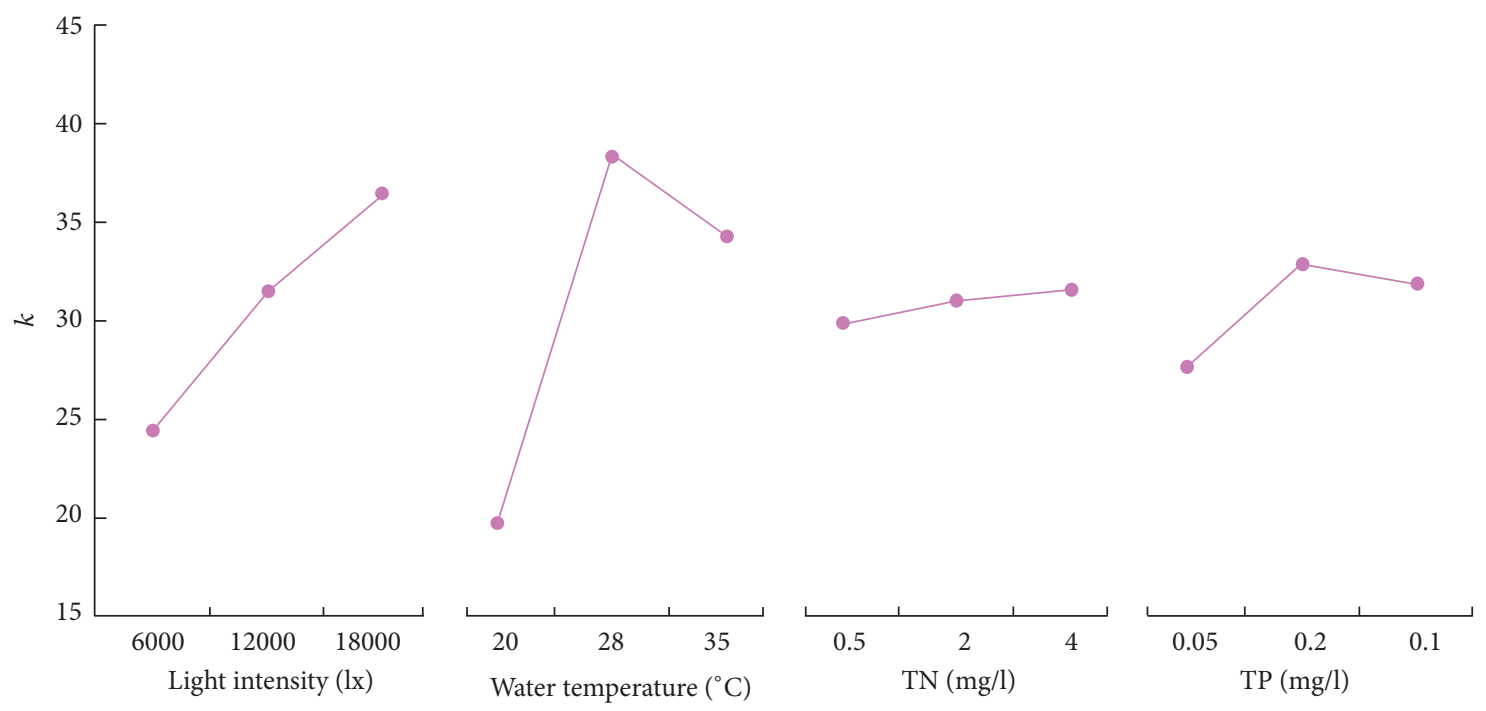

FIgURE 1: $\mathrm{L}_{9}\left(3^{4}\right)$ orthogonal experiment: intuitive analysis diagram of algae with largest stock on hand.
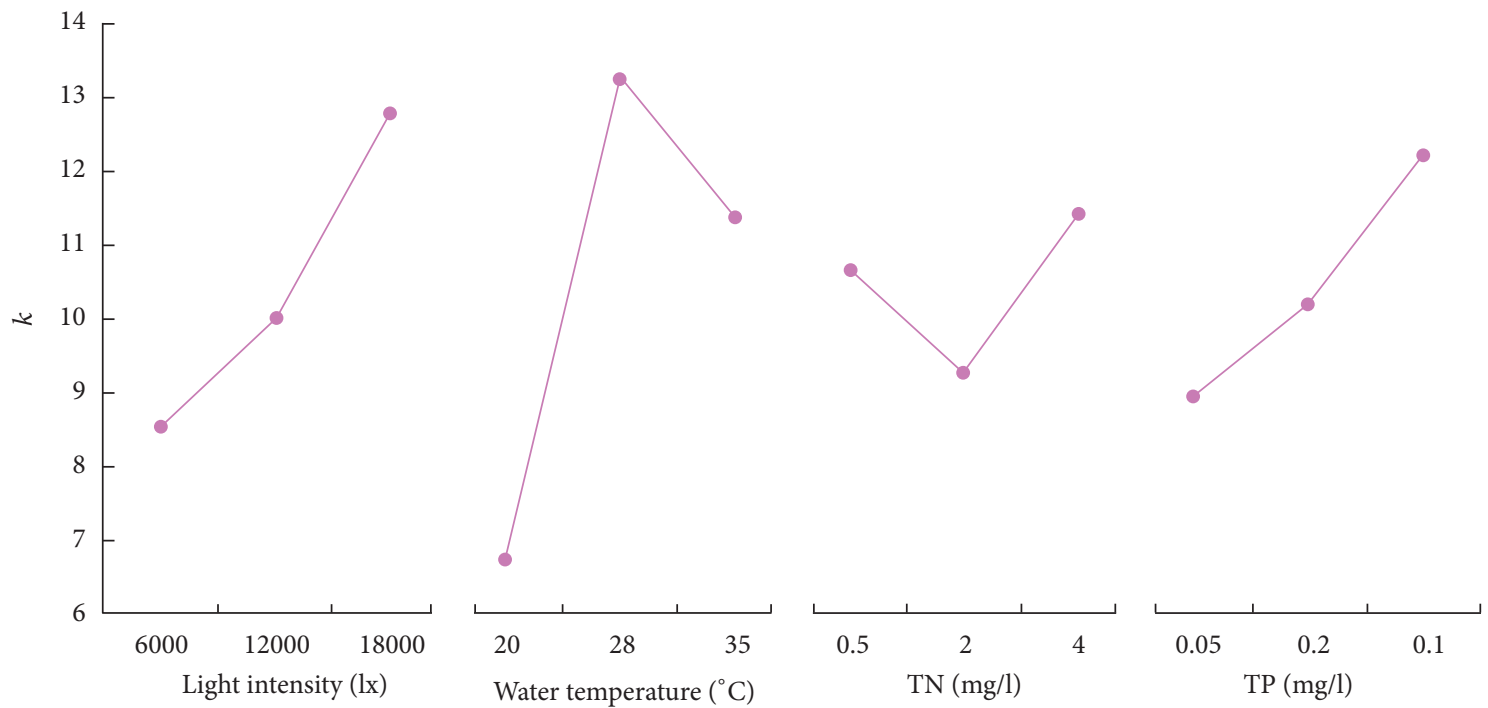

FIGURE 2: $\mathrm{L}_{9}\left(3^{4}\right)$ orthogonal experiment intuitive analysis diagram of algae maximum daily growth rate.

TABLE 3: Data summary table of orthogonal experiment results.

\begin{tabular}{|c|c|c|c|c|c|c|c|c|}
\hline & $\begin{array}{l}\text { Light intensity } \\
(\mathrm{lx})\end{array}$ & $\begin{array}{l}\text { Water temperature } \\
\left({ }^{\circ} \mathrm{C}\right)\end{array}$ & $\begin{array}{l}\mathrm{TN} \\
(\mathrm{mg}) \\
\end{array}$ & $\begin{array}{c}\mathrm{TP} \\
(\mathrm{mg}) \\
\end{array}$ & $\begin{array}{c}\mathrm{N} / \mathrm{P} \text { ratio } \\
(\mathrm{mole} \text { ratio })\end{array}$ & $\begin{array}{c}\text { Number of } \\
\text { experiment days }\end{array}$ & $\begin{array}{c}\text { Experimental results } \\
\text { chl-a/ }(\mu \mathrm{g} / \mathrm{L})\end{array}$ & $\begin{array}{c}\text { Experimental results } \\
(\mu \mathrm{g} /(\mathrm{L} \cdot \mathrm{d}))\end{array}$ \\
\hline 1 & 6000 & 20 & 0.5 & 0.05 & 22.14 & 12 & 9.3 & 3.5 \\
\hline 2 & 6000 & 28 & 2 & 0.2 & 22.14 & 14 & 34.3 & 9.9 \\
\hline 3 & 6000 & 35 & 4 & 0.1 & 88.57 & 13 & 29.8 & 12.2 \\
\hline 4 & 12000 & 20 & 2 & 0.1 & 44.29 & 15 & 21.7 & 6.9 \\
\hline 5 & 12000 & 28 & 4 & 0.05 & 177.14 & 15 & 36.7 & 12.3 \\
\hline 6 & 12000 & 35 & 0.5 & 0.2 & 5.54 & 15 & 36.1 & 10.9 \\
\hline 7 & 18000 & 20 & 4 & 0.2 & 44.29 & 14 & 28.2 & 9.8 \\
\hline 8 & 18000 & 28 & 0.5 & 0.1 & 11.07 & 14 & 44.1 & 17.6 \\
\hline 9 & 18000 & 35 & 2 & 0.05 & 88.57 & 14 & 37.1 & 11 \\
\hline
\end{tabular}


TABLE 4: $\mathrm{L}_{9}\left(3^{4}\right)$ orthogonal experiment range analysis of the maximum standing crop of algae.

\begin{tabular}{|c|c|c|c|c|c|}
\hline Number & Light intensity (lx) & Water temperature $\left({ }^{\circ} \mathrm{C}\right)$ & $\mathrm{TN}(\mathrm{mg} / \mathrm{L})$ & $\mathrm{TP}(\mathrm{mg} / \mathrm{L})$ & chl_a/ $(\mu \mathrm{g} / \mathrm{L})$ \\
\hline 1 & 6000 & 20 & 0.5 & 0.05 & 9.3 \\
\hline 2 & 6000 & 28 & 2 & 0.2 & 34.3 \\
\hline 3 & 6000 & 35 & 4 & 0.1 & 29.8 \\
\hline 4 & 12000 & 20 & 2 & 0.1 & 21.7 \\
\hline 5 & 12000 & 28 & 4 & 0.05 & 36.7 \\
\hline 6 & 12000 & 35 & 0.5 & 0.2 & 36.1 \\
\hline 7 & 18000 & 20 & 4 & 0.2 & 28.2 \\
\hline 8 & 18000 & 28 & 0.5 & 0.1 & 44.1 \\
\hline 9 & 18000 & 35 & 2 & 0.05 & 37.1 \\
\hline$k 1=K 1 / 3$ & 24.467 & 19.733 & 29.833 & 27.7 & \\
\hline$k 2=K 2 / 3$ & 31.5 & 38.367 & 31.033 & 32.867 & \\
\hline$k 3=K 3 / 3$ & 36.467 & 34.333 & 31.567 & 31.867 & \\
\hline$R$ & 12 & 18.634 & 1.734 & 5.167 & \\
\hline
\end{tabular}

TABLE 5: $\mathrm{L}_{9}\left(3^{4}\right)$ orthogonal experiment range analysis of the maximum daily growth rate of algae.

\begin{tabular}{|c|c|c|c|c|c|}
\hline Number & Light intensity (lx) & Water temperature $\left({ }^{\circ} \mathrm{C}\right)$ & $\mathrm{TN}(\mathrm{mg} / \mathrm{L})$ & $\mathrm{TP}(\mathrm{mg} / \mathrm{L})$ & chl_a/( $\mu \mathrm{g} / \mathrm{L})$ \\
\hline 1 & 6000 & 20 & 0.5 & 0.05 & 3.5 \\
\hline 2 & 6000 & 28 & 2 & 0.2 & 9.9 \\
\hline 3 & 6000 & 35 & 4 & 0.1 & 12.2 \\
\hline 4 & 12000 & 20 & 2 & 0.1 & 6.9 \\
\hline 5 & 12000 & 28 & 4 & 0.05 & 12.3 \\
\hline 6 & 12000 & 35 & 0.5 & 0.2 & 10.9 \\
\hline 7 & 18000 & 20 & 4 & 0.2 & 9.8 \\
\hline 8 & 18000 & 28 & 0.5 & 0.1 & 17.6 \\
\hline 9 & 18000 & 35 & 2 & 0.05 & 11 \\
\hline$k 1=K 1 / 3$ & 8.533 & 6.733 & 10.667 & 8.933 & \\
\hline$k 2=K 2 / 3$ & 10.033 & 13.267 & 9.267 & 10.2 & \\
\hline$k 3=K 3 / 3$ & 12.8 & 11.367 & 11.433 & 12.233 & \\
\hline$R$ & 4.267 & 6.534 & 2.166 & 3.3 & \\
\hline
\end{tabular}

When the light, temperature, total phosphorus, total nitrogen, and other conditions are sufficient, the chloroplast can convert inorganic phosphate and ADP to ATP, and the chloroplast absorbs light energy stored in the high-energy phosphate bonds of ATP to promote the growth of the algae. Under interaction with the optical system, the light energy is used to absorb and decompose water: $\mathrm{O}_{2}$ is released, and ATP and NADPH are produced. The chemical reaction can be expressed as formula (1).

$$
\begin{gathered}
2 \mathrm{ADP}+2 P_{i}+2 \mathrm{NADP}^{+}+\mathrm{H}_{2} \mathrm{O} \longrightarrow \\
2 \mathrm{ATP}+\mathrm{O}_{2}+2 \mathrm{NADPH}+2 \mathrm{H}^{+} .
\end{gathered}
$$

When there is insufficient light, the chloroplast uses the chemical energy of NADPH and ATP produced by the photosynthesis reaction to reduce $\mathrm{CO}_{2}$ to sugars and release the energy bond in high-energy phosphate for the decomposition of algae. This chemical reaction can be expressed by formula (2).

$$
\begin{gathered}
6 \mathrm{CO}_{2}+18 \mathrm{ATP}+12 \mathrm{NADPH} \longrightarrow \\
\mathrm{C}_{6} \mathrm{H}_{12} \mathrm{O}_{6}+18 \mathrm{ADP}+18 P_{i}+12 \mathrm{NADP}^{+} .
\end{gathered}
$$

In fact, in the process of algae growth, reactions (1) and (2) occur in parallel at the same time, but during the early and late stage and under different conditions of bloom outbreaks the proportion of the reactions varies.

\subsection{Evaluation Index Extraction of Water Eutrophication} Based on Experiment. According to the orthogonal experiment results, in the process of water eutrophication, water temperature, illumination, total phosphorus, and total nitrogen are important factors in the bloom formation. There are also physical, chemical, and biological indicators that affect water status. Transparency is the most commonly used 
TABLE 6: Principal component analysis results for secondary variables.

\begin{tabular}{|c|c|c|c|c|c|c|c|c|}
\hline \multicolumn{9}{|c|}{ Principal component factors } \\
\hline Principal component & WT & SD & Dissolved oxygen & $\mathrm{EC}$ & $\mathrm{pH}$ & $\mathrm{TP}$ & TN & chl_a \\
\hline 1 & -0.4528 & 0.4395 & 0.2273 & 0.4395 & -0.3358 & -0.1278 & 0.1454 & -0.4546 \\
\hline 2 & -0.1856 & -0.0259 & 0.0588 & -0.0299 & -0.2366 & 0.6671 & -0.6744 & -0.0683 \\
\hline 3 & -0.008 & 0.1417 & -0.7894 & 0.0282 & -0.5392 & 0.0468 & 0.1411 & 0.2078 \\
\hline 4 & 0.4036 & 0.1324 & 0.1128 & -0.0649 & -0.033 & 0.6424 & 0.5694 & -0.2544 \\
\hline 5 & -0.1772 & -0.4980 & -0.2033 & 0.7202 & 0.2869 & 0.2335 & 0.1428 & 0.0578 \\
\hline 6 & 0.0185 & -0.5936 & 0.3987 & -0.0450 & -0.6553 & -0.0992 & 0.1713 & 0.1307 \\
\hline
\end{tabular}

physical indicator. Total nitrogen and total phosphorus can correctly reflect the potential level of biological productivity of water and provide a better indicator for the judgment and control of water bloom. Some dominant populations of biological communities in the water body can be used as biological indicators. For a soft measurement system for eutrophication evaluation, the selection of the secondary variables, based on comprehensive analysis of the ecological conditions and the test index data of different rivers and lakes, can obtain more objective factors. For availability of indicators, WT, SD, Dissolved Oxygen, EC (Electrical conductivity), and $\mathrm{pH}$ are measured by YSI 6600 multifunction water quality on-line measuring instrument. The measurement method of TP is ammonium molybdate spectrophotometric method by GB 11893-89 in China. The measurement method of TN is potassium sulfate oxidation-ultraviolet spectrophotometry by GB 11894-89 in China. Light intensity is measured by weather station. COD is measured by potassium permanganate method which is also called potassium permanganate index. Light density is measured by SMARTAS813.

To determine the main factors influencing water bloom, the principal component analysis method is used to analyze the data, and the secondary variables of the evaluation model are determined. The contribution results from the principal component operation are shown in Table 6 .

Table 6 shows that the contribution coefficients of TW, SD, EC, and chl_a are larger in the first principal component, while the contribution coefficients of TP and TN are larger in the second principal component. The main factors influencing bloom growth in the orthogonal experiment are weighed and combined with the biology of water eutrophication and information related to the COD description, identifying chl_a, TP, TN, COD, and SD as the main factors in eutrophication. Meanwhile, based on the results of principal component analysis, the weights of the five factors chl_a, $\mathrm{TP}, \mathrm{TN}, \mathrm{COD}$, and SD in eutrophication assessment are, respectively, $0.27,0.2,0.2,0.13$, and 0.2 .

3.3. The Water Eutrophication Application. The Bayesian method is used to evaluate the probability of event occurrence to describe the stochastic uncertainty and correlation of water quality variables. In the evaluation of water eutrophication, the sample space of random events is $\Omega$; water samples $A \in$ $\Omega ; B_{i}(i=1,2, \ldots, s)$ indicate that the water eutrophication has $s$ evaluation levels; $P\left(B_{i}\right)$ expresses that water is affiliated with the incidence of the level $B_{i}$; and $P\left(B_{i}\right)>0$ is an ex ante estimate of the probability of $S$ species level and is a prior probability, as there are five levels in the evaluation of eutrophication, so $P\left(B_{i}\right)=0.2$. When $P(A)>0$, the Bayesian formula is

$$
P\left(\frac{B_{i}}{A_{k j}}\right)=\frac{P\left(B_{i}\right) P\left(A_{k j} / B_{i}\right)}{\sum_{j=1}^{s} P\left(B_{j}\right) P\left(A_{k j} / B_{j}\right)},
$$

where $A_{k j}$ is the $j$ th water quality index value of the $k$ th water sample; $j=1,2, \ldots, m ; k=1,2, \ldots, n$.

$P\left(B_{i} / A_{k j}\right)$ reflects a new understanding of the possibility of the $S$ species level in the presence of an index $A$ and indicates the nutrition level probability in the process of lake eutrophication, so it is also called the posterior probability.

$P\left(A_{k j} / B_{i}\right)$ reflects the fact that the water quality indicators $A$ indicate a certain level of eutrophication with the corresponding probability. The geometric probability method of distance representation used by $P\left(A_{k j} / B_{i}\right)$ calculates the reciprocal of the absolute value of the distance between the index value of a water quality sample and the eutrophication control standard value, as shown in formula (4).

$$
P\left(\frac{A_{k j}}{B_{i}}\right)=\frac{\left(1 / L_{j i}\right)}{\left(\sum_{i=1}^{s} 1 / L_{j i}\right)},
$$

where $L_{j i}=\left|A_{k j}-B_{i j}\right|+0.001$, and $B_{i j}$ is the arithmetic mean of the upper and lower bounds of the $i$ th eutrophication level of the indicator $j$.

The comprehensive value of water eutrophication assessment is based on the conditional probability-weighted calculation of the single index, as shown in formula (5).

$$
P_{i}=\sum_{j=1}^{m} W_{j} P\left(\frac{B_{i}}{A_{k j}}\right) .
$$

Xihai, Qianhai, Houhai, and Yuyuantan of Beijing, four water quality-monitoring data locations, are chosen for evaluation by the Bayesian method. The specific information on the monitoring sites, time, and water quality data is shown in Table 7.

All levels of lakes were compared to maximize the corresponding probability: the corresponding level of the lake is the eutrophication status of the lake. The probability of the results evaluated using the Bayesian network is shown in Table 8.

We set evaluation result of expert opinion as the standard. Using the same calculation method to evaluate the water 
TABLE 7: Water quality information at quality monitoring points.

\begin{tabular}{|c|c|c|c|c|c|c|c|c|}
\hline & Year & Month & Date & Chl_a $\left(\mathrm{mg} / \mathrm{m}^{3}\right)$ & $\mathrm{TP}\left(\mathrm{mg} / \mathrm{m}^{3}\right)$ & $\mathrm{TN}\left(\mathrm{mg} / \mathrm{m}^{3}\right)$ & $\mathrm{COD}(\mathrm{mg} / \mathrm{L})$ & $\mathrm{SD}(/ \mathrm{m})$ \\
\hline Xihai & 2012 & 6 & 6 & 17.74 & 80 & 2370 & 14.80 & 0.70 \\
\hline Xihai & 2013 & 6 & 5 & 21.50 & 60 & 3140 & 10.40 & 0.64 \\
\hline Xihai & 2013 & 7 & 3 & 7.17 & 30 & 1730 & 11.00 & 0.65 \\
\hline Xihai & 2014 & 8 & 5 & 23.20 & 60 & 2620 & 12.70 & 0.40 \\
\hline Qianhai & 2012 & 5 & 8 & 6.37 & 70 & 2740 & 13.50 & 1.50 \\
\hline Qianhai & 2013 & 6 & 5 & 8.87 & 40 & 2340 & 10.90 & 1.00 \\
\hline Qianhai & 2014 & 7 & 8 & 26.21 & 50 & 2110 & 9.40 & 0.80 \\
\hline Qianhai & 2014 & 8 & 5 & 24.57 & 30 & 2310 & 8.60 & 0.40 \\
\hline Beihai & 2013 & 6 & 5 & 23.38 & 80 & 1420 & 14.60 & 0.45 \\
\hline Beihai & 2013 & 7 & 3 & 33.22 & 60 & 1040 & 15.10 & 0.62 \\
\hline Yuyuantan & 2014 & 6 & 4 & 4.10 & 20 & 2200 & 35.10 & 0.40 \\
\hline Yuyuantan & 2014 & 7 & 9 & 16.38 & 50 & 2940 & 29.10 & 0.38 \\
\hline
\end{tabular}

TABLE 8: Bayesian evaluation results for water eutrophication.

\begin{tabular}{lcccccccccc}
\hline & Year & Month & Date & I & II & III & IV & V & Evaluation level \\
\hline Xihai & 2012 & 6 & 6 & 0.1997 & 0.2102 & 0.1979 & 0.1923 & 0.1989 & II \\
Xihai & 2013 & 6 & 5 & 0.1874 & 0.2053 & 0.1923 & 0.1975 & 0.1991 & II \\
Xihai & 2013 & 7 & 3 & 0.219 & 0.2012 & 0.194 & 0.1971 & 0.1991 & I \\
Xihai & 2014 & 8 & 5 & 0.1914 & 0.2077 & 0.1992 & 0.1993 & 0.1996 & II \\
Qianhai & 2012 & 5 & 8 & 0.2252 & 0.2011 & 0.1892 & 0.2852 & 0.1972 & IV \\
Qianhai & 2013 & 6 & 5 & 0.2117 & 0.2034 & 0.1855 & 0.1942 & 0.1984 & I \\
Qianhai & 2014 & 7 & 8 & 0.1824 & 0.2009 & 0.1685 & 0.1967 & 0.1989 & II \\
Qianhai & 2014 & 8 & 5 & 0.1856 & 0.1924 & 0.1923 & 0.2005 & 0.1996 & IV \\
Beihai & 2013 & 6 & 5 & 0.1933 & 0.2024 & 0.2 & 0.1977 & 0.1994 & II \\
Beihai & 2013 & 7 & 3 & 0.1896 & 0.2056 & 0.1992 & 0.1932 & 0.199 & II \\
Yuyuantan & 2014 & 6 & 4 & 0.2508 & 0.2068 & 0.2 & 0.1998 & 0.1983 & I \\
Yuyuantan & 2014 & 7 & 9 & 0.2184 & 0.2263 & 0.2 & 0.1998 & 0.1991 & II \\
\hline
\end{tabular}

quality of the 100 major lakes in our country and comparing the bias evaluation method with the single factor evaluation method of $90 \%$, comprehensive evaluation method of $94 \%$, and expert opinion set by national standards, we concluded that the evaluation result accuracy of the Bayesian method is $96 \%$, and the overall trend of the evaluation results is consistent with expert opinion, which proves that this method is applicable to water eutrophication assessment.

\section{Conclusions}

The water eutrophication process is a complex mechanism involving many factors. To determine main factors, an orthogonal experiment was designed to analyze the key roles of illumination. Water temperature, total phosphorus, and total nitrogen in water eutrophication can all have large effect on algae growth by analyzing range value. These factors are determined as main factor. Moreover, we analyze the monitoring data of water quality to further determine main factors. By utilizing principal component analysis, we can extract the larger contribution of the principal components to the water eutrophication. Its results ultimately confirm the eutrophication evaluation indexes including chlorophyll a, total phosphorus, total nitrogen, COD, and transparency. Finally, in view of the uncertainty in the process of evaluation, the application of Bayesian theory in eutrophication assessment was examined. Compared with single factor evaluation method, comprehensive evaluation method, and expert opinion, Bayesian method was found to offer higher accuracy of $96 \%$ in eutrophication assessment.

\section{Conflicts of Interest}

The authors declare that they have no conflicts of interest.

\section{Acknowledgments}

This study is supported by the NSFC under Grant (no. 51179002); Beijing Municipal Education Commission Science and Technology Plan Key Projects (no. KZ201510011011); Beijing Universities and Colleges Enhancing Scientific and Technological Innovation Capability Project (no. PXM2014_014213_000033). All support is gratefully acknowledged. 


\section{References}

[1] Anonymity, "Ministry of environmental protection issued '2013 China Environmental Status Bulletin," China Environmental Science, vol. 34, no. 6, pp. 1379-1379, 2014.

[2] D. J. Conley, H. W. Paerl, R. W. Howarth et al., "Ecologycontrolling eutrophication: nitrogen and phosphorus," Science, vol. 323, no. 5917, pp. 1014-1015, 2009.

[3] S. R. Carpenter, D. Ludwig, and W. A. Brock, "Management of eutrophication for lakes subject to potentially irreversible change," Ecological Applications, vol. 9, no. 3, pp. 751-771, 1999.

[4] H. W. Paerl and J. Huisman, "Blooms like it hot," Science, vol. 320, no. 5872, pp. 57-58, 2008.

[5] H. W. Paerl, N. S. Hall, and E. S. Calandrino, "Controlling harmful cyanobacterial blooms in a world experiencing anthropogenic and climatic-induced change," Science of the Total Environment, vol. 409, no. 10, pp. 1739-1745, 2011.

[6] Q. L. Wu, P. Xie, L. Y. Yang et al., "Ecological consequences of cyanobacetrial blooms in lakes and their countermeasures," in Advances in Earth Science, vol. 11, pp. 1115-1123, 2008.

[7] J. Zhang, T. Xiao, D. Huang, S. M. Liu, and J. Fang, "Editorial: eutrophication and hypoxia and their impacts on the ecosystem of the Changjiang Estuary and adjacent coastal environment," Journal of Marine Systems, vol. 154, pp. 1-4, 2016.

[8] M. W. Matthews and D. Odermatt, "Improved algorithm for routine monitoring of cyanobacteria and eutrophication in inland and near-coastal waters," Remote Sensing of Environment, vol. 156, pp. 374-382, 2015.

[9] D. A. Caron, M.-È. Garneau, E. Seubert et al., "Harmful algae and their potential impacts on desalination operations off southern California," Water Research, vol. 44, no. 2, pp. 385-416, 2010.

[10] W. K. Dodds, W. W. Bouska, J. L. Eitzmann et al., "Eutrophication of U.S. freshwaters: analysis of potential economic damages," Environmental Science and Technology, vol. 43, no. 1, pp. 12-19, 2009.

[11] Z. Liu, X. Wang, and L. Cui, Water Environment Monitoring Evaluation and Water Bloom Intelligent Prediction Method and Emergency Management Decision Making System, Chemical Industry Press, 2013.

[12] L. Wei, Progress in Environmental Hydraulics, Water Conservancy and Electric Power University Press, 1998.

[13] V. H. Smith and D. W. Schindler, "Eutrophication science: where do we go from here?" Trends in Ecology and Evolution, vol. 24, no. 4, pp. 201-207, 2009.

[14] P. J. S. Franks, "NPZ models of plankton dynamics: their construction, coupling to physics, and application," Journal of Oceanography, vol. 58, no. 2, pp. 379-387, 2002.

[15] Q. Chen and A. E. Mynett, "Integration of data mining techniques and heuristic knowledge in fuzzy logic modelling of eutrophication in Taihu Lake," Ecological Modelling, vol. 162, no. 1-2, pp. 55-67, 2003.

[16] S. E. Jørgensen, "Structural dynamic model," Ecological Modelling, vol. 31, no. 1-4, pp. 1-9, 1986.

[17] D. D. Kane, J. D. Conroy, R. P. Richards, D. B. Baker, and D. A. Culver, "Re-eutrophication of Lake Erie: correlations between tributary nutrient loads and phytoplankton biomass," Journal of Great Lakes Research, vol. 40, no. 3, pp. 496-501, 2014.

[18] R. A. Vollenweider, "Input-output models: with special reference to the phosphorus loading concept in limnology," Schweizerische Zeitschrift für Hydrologie, vol. 37, no. 1, pp. 53-84, 1975.
[19] A. M. Caires, S. Chandra, B. L. Hayford, and M. E. Wittmann, "Four decades of change: dramatic loss of zoobenthos in an oligotrophic lake exhibiting gradual eutrophication," Freshwater Science, vol. 32, no. 3, pp. 692-705, 2013.

[20] S. E. Jørgensen, H. Mejer, and M. Friis, "Examination of a lake model," Ecological Modelling, vol. 4, no. 2-3, pp. 253-278, 1978.

[21] J. H. Andersen, J. Carstensen, D. J. Conley et al., "Long-term temporal and spatial trends in eutrophication status of the Baltic Sea," Biological Reviews, vol. 92, no. 1, pp. 135-149, 2017.

[22] B. Narasimhan, R. Srinivasan, S. T. Bednarz, M. R. Ernst, and P. M. Allen, "A comprehensive modeling approach for reservoir water quality assessment and management due to point and nonpoint source pollution," Transactions of the ASABE, vol. 53, no. 5, pp. 1605-1617, 2010.

[23] F. Kong, R. Ma, J. Gao et al., "The theory and practice of the prevention, prediction and early warning of cyanobacteria bloom in Taihu Lake," Lake Science, vol. 3, pp. 314-328, 2009.

[24] J. D. Wehr, L. M. Brown, and I. E. Vanderelst, "Hydrogen ion buffering of culture media for algae from moderately acidic, oligotrophic waters," Journal of Phycology, vol. 22, no. 1, pp. 8894, 1986.

[25] T.-Y. Long, P.-R. Zhou, and L. Wu, "The simulating experiment for the impacts of environmental factors on Spring algae growth in Xiangxi River," China Environmental Science, vol. 31, no. 2, pp. 327-331, 2011.

[26] YSI 660 6-Series Multi Parameter Water Quality Sondes. User Manual, YSI Incorporated, http://www.xylem-analytics.com.au/ media/pdfs/ysi-6-series-manual_001.pdf. 

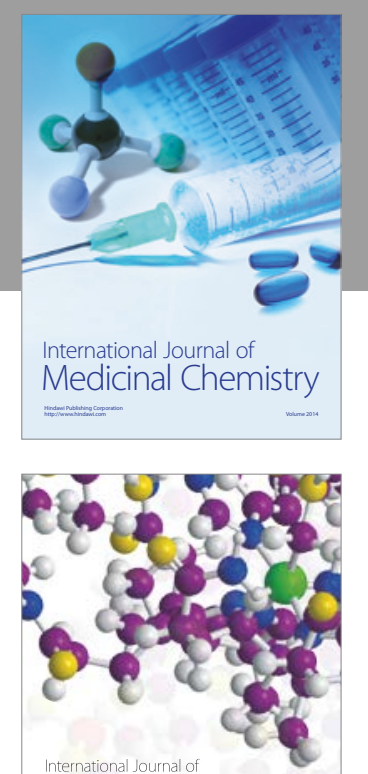

Carbohydrate Chemistry

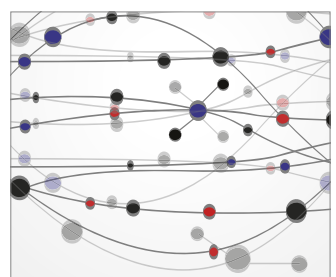

The Scientific World Journal
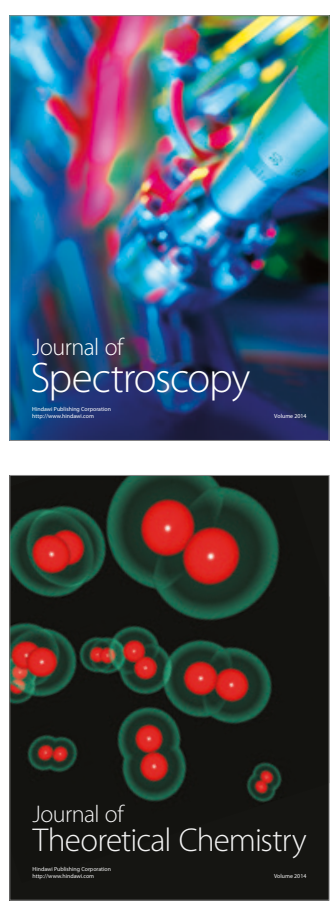
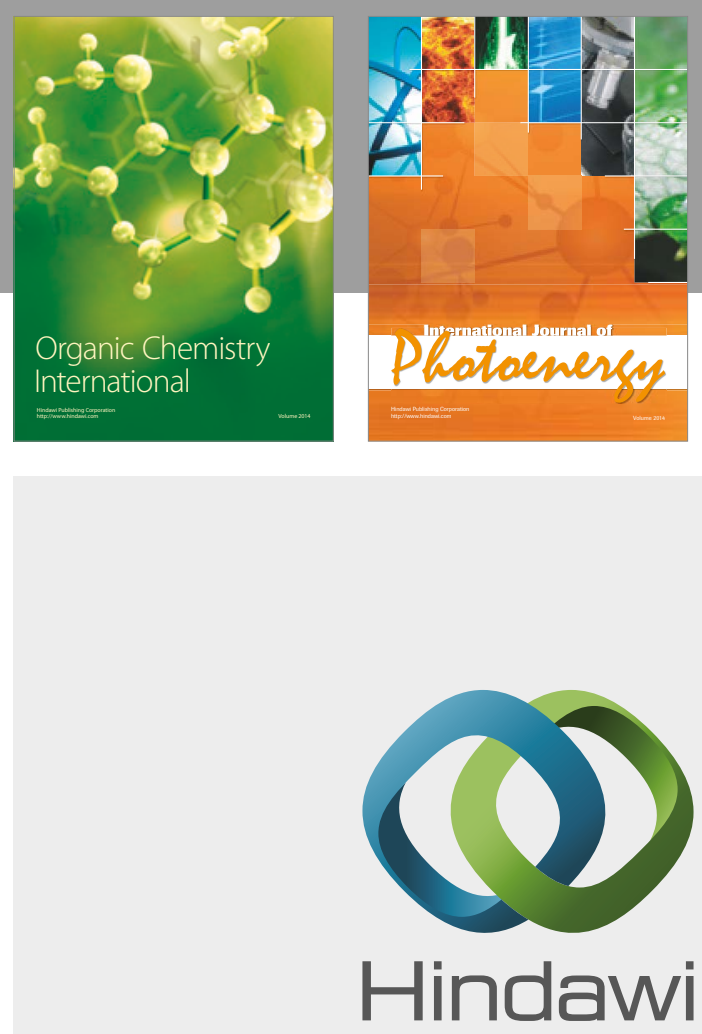

Submit your manuscripts at

https://www.hindawi.com

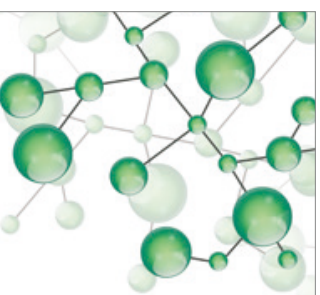

International Journal of

Inorganic Chemistry

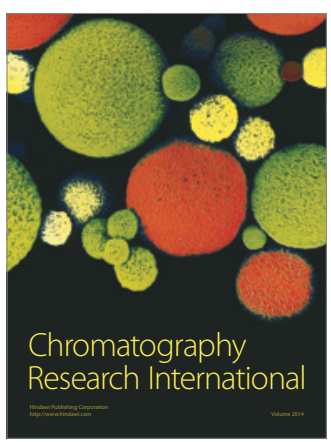

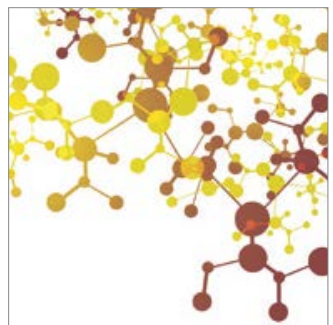

Applied Chemistry
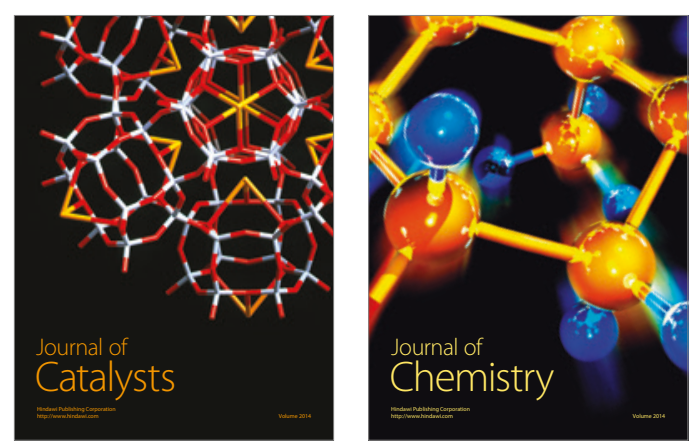
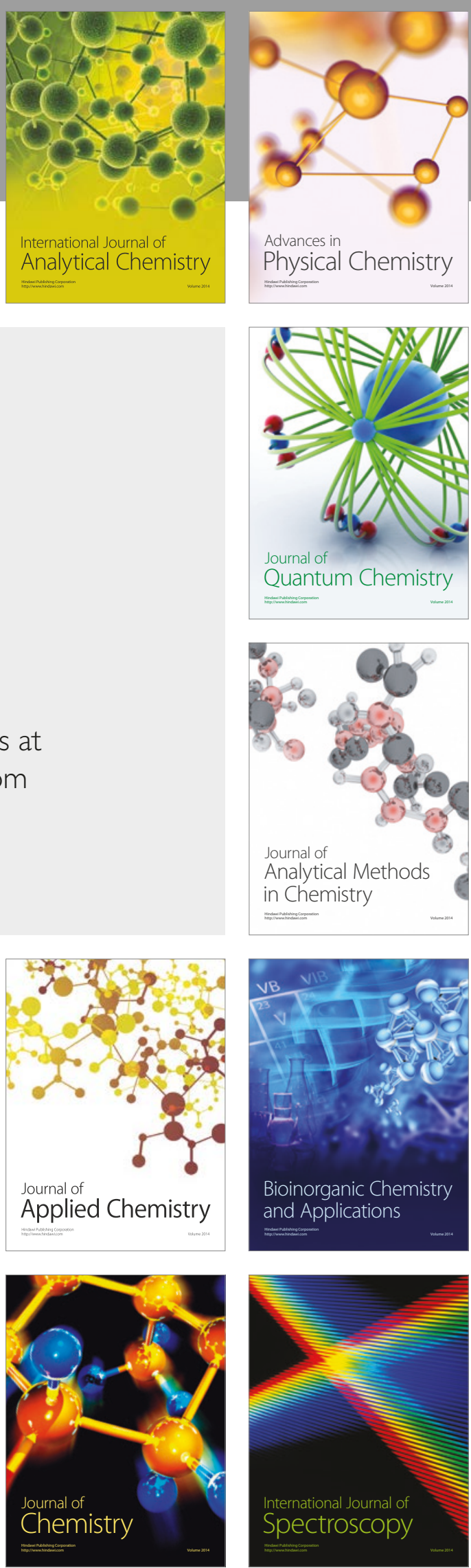